\title{
STTEP by STEPP in the spirit of Umuntu ungumuntu ngabantu
}

\author{
Caroline van Niekerk and Maria Typpo \\ Department of Music, University of Pretoria, Pretoria, South Africa \\ caroline@mweb.co.za, maria.typpo@hotmail.com
}

In a recent article, 'Sttepping in the right direction? Western classical music in an orchestral programme for disadvantaged African youth', 'sttepping' was noted as no spelling error. The same applies here; reference is to STTEP Music School, an outreach project at the University of Pretoria. STTEP teaches the playing of orchestral instruments, plus background areas like music theory, to disadvantaged learners. Ethnographic and case study research of STTEP, its teachers, pupils and administrators, over the period 2005-2009 was conducted within a sociological meta-theoretical framework. From the hybrid data obtained, conclusions have been drawn, including on observed effects of the African philosophy Ubuntu.

\section{Introduction}

After the International Society for Music Education (ISME) world conference in 1998 in Pretoria, the Finnish branch of ISME formulated an intercultural ${ }^{1}$ development project with the South African STTEP ${ }^{2}$ Music School, ${ }^{3}$ which focuses on teaching Western orchestral instruments to disadvantaged black children and youth ${ }^{4}$ from townships ${ }^{5}$ around the city of Pretoria, South Africa. The Music School of the Municipality of Jyväskylä in Finland took a specific initiative as a friendship school to STTEP, and two cooperative music camps were organised in South Africa in the years 2000-2002. In July 2001, nine STTEP students visited Finland; two were afforded this opportunity in 2009. During these visits STTEP pupils worked together with Mauno Järvelä, ${ }^{6}$ a famous Finnish music pedagogue and folk fiddler.

The first author of this article serves on the STTEP Board of Directors, and works in the Department of Music of the University of Pretoria (UP), on the campus of which STTEP was offered free accommodation when having to move from its previous location. She thus serves as a link between the UP Music Department and STTEP. She also coordinates the exchange programme between the universities of Pretoria and Jyväskylä. The second author worked for six months as a violin teacher at STTEP, during her time in South Africa in 2005 as an exchange student from Finland at UP, and subsequently as a researcher, using the project as the basis for her research work back at the University of Jyväskylä.

In this article the authors wish to demonstrate the manifestation of Ubuntu ${ }^{7}$ : pupils see STTEP, and the opportunity to play an instrument, as something very significant. STTEP gives them meaningful activity especially on Saturdays, when they are free from school, although the school's weekday afternoon programme has grown increasingly in recent years. 


\section{Background}

In 1995 STTEP was launched, a few years after the husband and wife team of Philip ${ }^{8}$ and Julie Clifford moved to Pretoria from the UK. Julie was working as a violinist in the orchestra of the State Theatre, in the centre of the country's capital city, when the Mercedes Benz motor company granted funds for black orchestral cadets to join the orchestra and be educated as professional musicians. Yet there were no such potential cadets with even the basic skills needed to join the project. Julie Clifford, together with the then State Theatre orchestra conductor, Michael Hankinson, contacted some churches in surrounding townships, organised small orchestral concerts there and during these events tried to ascertain the wishes of the local residents regarding music education for themselves and their children. A group of 170 adults, mostly choir singers, were interested to learn Western music theory and staff notation. Many took their children with them to the lessons which were organised at that time at the State Theatre. Children became interested in the orchestral instruments which they saw there, and the idea of STTEP Music School was born.

Just less than a decade later, and with Philip Clifford having joined his wife Julie in running the project, some of the STTEP students were already aiming to be professional musicians. However, for most of the children, playing this music was and is just a hobby, although one which gives more meaning and flavour to their lives. ${ }^{9}$ Regardless of their age, most students initially have very little or no background in music studies. STTEP tuition is started from basics. The main STTEP working day is Saturday: students arrive in the morning and then have individual instrumental lessons, orchestral rehearsals, music theory, history and aural training throughout the day. STTEP rents out instruments for a small fee: care is taken that learning to play an instrument is affordable, but commitment and responsibility for instruments must be shown.

Students come from townships and suburban areas around Pretoria and bus transportation to and fro makes the programme available to all. Despite the expense of the transport, as a large item of STTEP's budget, it has two important advantages: those children who come by bus attend more regularly than if they had to depend on other transport. Pupils who come from a wide geographic area are also able to mix - pupils from one township might not otherwise be able to cooperate regularly with pupils from another township, on another side of Pretoria. ${ }^{10}$

Several of the more advanced STTEP players work as assistant teachers, in addition to continuing with their own studies. Here Ubuntu is seen at work as they gain important experience of tuition and taking responsibility, at the same time giving valuable help, for example in language problems between a white, non-African language-speaking teacher and a black pupil whose home language is one of the nine indigenous such languages in South Africa. Some older players still come to school to assist and play even though they are in their twenties and have already started their own careers in a different direction. They function as mentors for the current STTEP pupils, in very much the ways described by Kafai et al. (2008) where mentors gain experiences that connect theory and practice, participating not only as more knowledgeable peers but also as facilitators, advisors and observers and reviewing assumptions about their own learning and mentoring. In this way, a genuine 'community of practice' is found (Ilari, 2010). 
Having provided a brief history of and operational information on STTEP, the theoretical lenses, through which the ethnographic and case study research for this article were viewed, will be described in the following section. These lenses were both specifically (South) African, as with Ubuntu, and international.

\section{Theoretical framework}

The background and theoretical basis for this article is very similar to that of the 2008 article by Van Niekerk and Salminen; the further work reported here was a continuation of that which preceded it. Research questions related to interviewees' musical background and activities and probed differences between music teaching and learning in South Africa and Europe.

In addition to intercultural education theories (see especially Buttjes \& Byram, 1991, p. 277), various social theories were considered. STTEP's activities were also viewed through the lens of the Ubuntu concept, a discussion of which is provided under that heading below. Expectancy-value theory appeared to become increasingly relevant as the results of STTEP's work were documented and considered. As a strand of motivation research, expectancy-value theory tries to offer a framework for understanding why individuals are sufficiently interested in activities that they believe might in future be important to them (see Pintrich \& Schunk, 2002). Four components are described: attainment value, intrinsic value, utility value and perceived cost of the activity. Although STTEP pupils' music activities are highly subsidised, the monetary cost can still be significant for some. However, cost also refers to time and effort needed to practise instruments and attend lessons, rehearsals and performances.

Culture and power relations issues and their pedagogical relevance have always been considered within STTEP. ${ }^{11}$ This is particularly important after nearly half a century of Apartheid ${ }^{12}$ policies. The 'disadvantaged' pupils are nearly all black Africans, whereas the two researchers are white (as are most teachers in the project), and can thus be seen as belonging to the racial grouping of the previous elite, and oppressors of the black majority in the country. ${ }^{13}$ However, the authors took heart from the 'social turn' of 'the last few decades of educational research', described by Belz and Müller-Hartmann (2003, pp. 71-73): 'This theoretical shift is in reference to the view that teachers, learners, learning, and teaching are always and everywhere embedded in cultural, historical, institutional, and power-structured contexts. Although these contexts bear significantly on the ultimate shape that learning and teaching assume, learners and teachers are not mere automatons caught in a tangle of macro-level forces; instead, their individual agencies are co-constructed by the interrelationships of their own desires, abilities, and histories and the particular mix of artefacts, cultures, institutions, people, and situations in which they are located and in which they interact ... Social realism provides a theoretical framework and concrete investigative methodology with which to examine and interpret complex social action.'

Societal theory and social realism, mentioned above, are also linked to social learning theory, one of the salient variables in music preference. The issue of the music preferences of STTEP pupils, mostly black Africans, in a country where Gospel is the number one selling music genre, and Western music often regarded as Eurocentric and elitist, is one of great interest. Social transformation theory is clearly relevant in South Africa, with its political 
history and resulting social problems. These problems still obtain to a large extent, but music education can play a positive role in their amelioration.

'Although education alone cannot change the face of many problems that exist today, it can influence the future by preparing the minds of young people to include a diversity of viewpoints, behaviors and values' (Cushner, 1998, p. 2). Elsewhere Cushner (1998, p. 6) notes that 'School programs and practice teaching Eurocentric (or any other 'centric') experience, heritage, and perspective that exclude the views of others must be transformed, and young people must be helped to develop the knowledge, motivation, and skill to challenge and change systems characterized by discrimination and oppression.' This article's authors may have been specifically concerned with the teaching of Western instruments and music theory to African children, but bore in mind that Intercultural sensitivity is not natural ... Education and training in intercultural communication is an approach to changing our 'natural' behaviour. With the concepts and skills developed in this field, we ask learners to transcend traditional ethnocentrism and to explore new relationships across cultural boundaries' (Bennett, 1993, p. 21). Furthermore, we endorse Schippers's note that musical identities can play a significant role in the process in which many societies 'appear to be moving from socially constructed to more individually constructed identities' (Schippers, 2010, p. 30).

The four approaches to multicultural ${ }^{14}$ education as identified by Eldering (1996) were considered: the disadvantage approach, the enrichment approach, the bicultural competence approach and the collective equality approach. The work in STTEP answers to the last three of these approaches, with the resultant advantages that Eldering describes from these foci. Although bearing in mind STTEP pupils' backgrounds, we believe in using music in the way described by Skyllstad, in his chapter in the book by Jandt (2004, p. 377): 'Music, dance and theatre are important arenas for training in democratic participation and conflict transformation. The cultural crises we now see unfolding may be traced to our modern societies discontinuing these vital processes of social learning ... Musical interaction creates social values.'

Helms's Racial Identity Theory, Banks's Typology of Ethnicity and Bennett's Developmental Model of Intercultural Sensitivity, as explored by McAllister and Irvine (2000), were considered. However, no one specific model has been followed nor cultural understanding focused on 'otherness', as Leeman and Reid (2006, p. 58) note that educational theory has tended to do. We rather agree with Woodrow et al. (1997, p. 3) that 'even theory ... is culturally created and leads to different conceptualisation in different societies'. Later in their book (1997, pp. 21-27) they describe the claims of the theories of collective identity as 'nothing less than obvious ... it seems that the array of theories of collective identity is more a question of food for thought than a fait accompli. It is probably where social psychology and the disciplines with which it is associated... prove the least certain in the prediction of events and the prevention of crises. All the more reason for further work.'

Having considered the research questions related to the specific interviewees, plus general differences between South African and European music teaching and learning, in the light of social and inter-/multicultural aspects of education theories, expectancy value theory and the Ubuntu concept, the research methodology will briefly be described. 


\section{Research methodology}

The basis for this article was ethnographic research and case studies, bearing in mind the strengths ('[h]igh construct validity; in-depth insights; establishing rapport with research subjects') and limitations ('[l]ack of generalisability of results; non-standardisation of measurement; data collection and analysis can be very time-consuming') of this type of research (see Mouton, 2001, pp. 149-150). The second author's observations were made both in the field, while in South Africa, and subsequently back in Finland, analysing videotapes of her teaching and reviewing the detailed diary she kept while in South Africa. Data-based analysis of material gathered, as a whole, was done by identifying themes and then subsequently resynthesising these into a coherent whole, as described by Hirsjärvi and Hurme (2000, p. 144). Later, brief questionnaires on Ubuntu were administered to both teachers and pupils by the first author, because of the clear importance of this philosophy revealed in the research.

The literature study was mainly based on material supplied by the founders of the project, the Cliffords, general background literature in fields such as education, cultural and musical identity, various social theories, Ubuntu and research reports during which STTEP pupils were utilised in music perception studies by other personnel of the University of Jyväskylä.

\section{Background information about interviewees}

Initially in South Africa Philip and Julie Clifford worked in their own fields, but having founded STTEP this became the main focus of both their working and private lives. Two other STTEP teachers of long standing who were interviewed were Snejana and Ivan Lazarov, originally from Bulgaria, from where they moved to South Africa in 1988. Both violinists, they started teaching at STTEP in 2002. The Cliffords were selected for openended interviewing because they were among the founders of the project, and continued with uninterrupted involvement. The Lazarovs were among the first teachers in STEPP and have continued their teaching, through all the chapters in the project's history. No other teachers have had the same degree of involvement; they come and go, and may see this teaching as merely a source of income.

\section{STTEP's direction and underlying philosophy}

Despite Mercedes Benz's original idea, STTEP's goals are not mainly to produce professional black instrument players and thus help the continuation of Western art music culture in South Africa - goals which are questioned both within and outside the country. The school founders have stressed repeatedly their main motivation - improving the lives of the pupils and developing their love for music - two aspects which are emphasised in varying degrees in different music outreach work elsewhere in the world. For example, in El Sistema, the National System of Youth and Children's Orchestras of Venezuela, 'Its 200 youth orchestras have provided a haven from crime and drugs for young people in the barrios ... the social benefits of El Sistema no doubt stem from the mere fact that it supplies some degree of structure and security in lives that had precious little before' (Ball, 2010, p. 7). The value of 
the music itself is also noted, but not to the extent of the title of an article on an American project: 'It's All About the Music' (Rauf, 2006, p. 4; see also White, 2008).

The direction the school follows is not only determined by its founders and fellowteachers, but is also reflected by pupils' perceptions of STTEP: this is clearly revealed in quotations from interviews conducted with some of them (Van Niekerk and Salminen, 2008).

Philip Clifford noted two important points: first, 'whereas a small group of STTEP's pupils took from their work with Finns a true inspiration ... too many others thought that they had got on to an escalator that would gently raise them to the top floor with no further effort ...' (email to the first author, dated 1 March 2007). The second point was: 'Looking back on the last ten years, we see that musically we have travelled further than we foresaw in, for example, 1999; BUT it is equally clear that we should have aimed much higher from the beginning, and that we now have to pay specific attention to the development of our most talented pupils.'

STTEP's philosophy is clearly student centred. Most teachers try to accommodate pupils' backgrounds and support pupil-initiated activity, and fusion music styles observed when pupils play together are a good example of the fruits of this attitude. Students are also asked for their opinions when important decisions are to be made. Yet the teaching methods and practical arrangements are very close to a traditional Western classical music school system - the background of all the teachers.

\section{Musical activities}

The STTEP orchestra works as an important social link between students from different areas and language groups. Instead of watching television, many pupils are now meeting their new friends and playing together during their free time. Encouragement in this is provided by the more specialised orchestra, known as AmAcademy. ${ }^{15}$ Pupils can be selected for AmAcademy from the large, general orchestra, in which all play, from the very youngest beginners, every Saturday.

STTEP pupils are proud of their musical activity, although not all their friends and families understand or support them. It is their own progress that develops their self-esteem and many have found their best friends in STTEP. Zillman and Gan (1997, p. 162) state that music is a primary objective of adolescents in industrialised society, and the large majority of STTEP pupils are adolescents. North and Hargreaves (1999, pp. 71-84) suggest that adolescents often prefer styles of music to which they relate in their own subjective way, or within a social group to which they belong. Although referring specifically to listening variables in music preference, a key author such as LeBlanc (1982) includes influence of peer group's listening preference, formal music experience, informal music experience and familiarity with music. All of these authors' points are borne out by STTEP participants.

The music surrounding STTEP students is mostly Western popular music. TV and radio music programmes are closely followed. Many pupils, though, still also have contact with their more traditional musical roots. Traditional songs are sung on special occasions and rituals, as well as sometimes when friends and family meet. However, in some cases parents do not teach their children about their roots, preferring to ensure that they fit in well in modern, largely Western society. 
Many students were first exposed to Western classical music at STTEP, and they have noted that they associated the genre with white people; not for them. However, after starting at STTEP they found this kind of music enriching their lives. STTEP's possibilities, friendly personnel and warm atmosphere are highly appreciated. A special flavour is also obtained from the school's international contacts, and the opportunities enjoyed as an outreach project of long-standing, also under the auspices of the largest residential university in South Africa, the University of Pretoria. This brings students into contact with the university as an institution, and its students as potential role models.

\section{Western and African music education}

As indicated before, the article's second author studied, taught music and also did fieldwork in South Africa for half a year in 2005. This experience showed some aspects of differences between Western and African music education. Both African and Western music education systems have a long history, but the way of teaching is usually different. In South Africa there are schools and projects, like STTEP, which are arranged very much like a Western classical music school system, but there is not a music education system in the Western manner as such among the indigenous people of the country. Comparing the situation between the European Union and South Africa, one notes how many South African music schools lack financial support, suitable facilities/venues, qualified music teachers and teaching material. This clearly affects students' progress.

The bigger companies are interested in investing money into something which will bring them money and music is not something that gives you return from what you invest. The return is in a different way...

Townships are very far ... they have not a place ... for example I got student ... very good ... but he can't practise at home ... and every time, when he comes ... He thought: I can't practise at home, I have to practise pizzicato, because of the neighbours. (Interview with Ivan and Snejana Lazarov, 3 September 2005)

How many problems are there, which they [students] don't say anything about, because they are embarrassed? How many times is it true that they can't practise at home, because their parents won't let them? I don't know. Five persons per family living in two rooms. How can you practise the violin, when can you practise the violin? I don't know. (Interview with Julie and Philip Clifford, 22 August 2005)

Whatever the circumstances about the people here are, I think most of them have quite a difficult time, because they don't have ... parents yet, who have learned instruments. So, their practising is particularly lonely ... (Interview with Julie and Philip Clifford, 22 August 2005)

STTEP pupils have demonstrated in their community that they can play classical, African traditional and crossover music on their Western classical instruments. The boundaries are fading and interest growing, with the long-term prospect that when STTEP students become parents some of them will surely want to send their children to a place like STTEP which will then enjoy stronger support from the parents and community. 
Now it starts being much more serious, interested in education. People now understand the importance of it, but I think also that time has changed. People have realized that this is an important part of their life ... I don't know the reason for it, but probably because economically now ... the country is much better in general. There is no fear of collapse on the economical side and people are more open to do things which are not connected straight to the surviving ... They can spend money on something which is very valuable for their life. Before it wasn't thinkable ... People are very serious about what they are doing. They want to learn. I am amazed how wonderful things are in South Africa. It's very pleasant to have the feeling that there is a great interest in music. (Interview with Ivan and Snejana Lazarov, 3 September 2005)

We must look to raising the musical standard of our school. Until now the idea of a cultural meeting place in the centre of Pretoria of the people from a huge area ... having a good time together, playing with each other has been good enough. It's not going to be good enough any more ... it is so important that things have to be managed and more effective ... (Interview with Julie and Philip Clifford, 22 August 2005)

African instrumental music teaching concentrates on joy and experiences, not so much on rules, as in Western teaching.

They [students] start really well, and because they couldn't play something perfectly, then she [teacher] would still keep going and they have to play it and achieve it, make them play it until they could play it. But then they never could play it, because they get so tired of it. And eventually they give it up, all of them. (Interview with Julie and Philip Clifford, 22 August 2005)

Western classical music education tends to be systematic and precise, requiring great patience from the students, especially from the beginners. According to Julie Clifford's experience, music teaching in South Africa progresses more quickly in the beginning, with pupils at first concentrating on how to play the music and only later learning more about technical aspects:

Things normally take a long time [in Europe], when you are teaching beginners ...

I threw it out of the window... I move them [students] very quickly at the beginning and then I come back ... It's a quite fine balancing job ... pushing them forward and yet making sure that you go back on the technical stuff. (Interview with Julie and Philip Clifford, 22 August 2005)

\section{Ubuntu}

The South African saying 'Umuntu ungumuntu ngabantu', the meaning of which can be translated as 'Man can only become fully human through his relationships with his fellow men', describes well the African philosophy of Ubuntu; the traditional African communal way of living, emphasising what Broodryk (2002, pp. 18-49) describes as the five Ubuntu values of humanness, caring, sharing, respect and compassion. This also influences music making. For the second author, in her experience in South Africa, it seemed notably natural for students to help each other, without a spirit of competitiveness. A communal way of making music also gives the audience a chance to participate. They are seen as an 
important part of performance: a community makes music, music belongs to everybody and everybody can learn music. Students' motivation and personal background, as well as teachers' encouragement, affect learning results more than ethnic background.

There are different difficulties for everyone and I would say there are more physical and mental difficulties to get the right thing to be able to focus on things to get that. Some of the children or adults who start are quicker than others, but there is no clear cut between races ... The main difference is the approach to that and also background. Some of the children from the townships come from very difficult families ... makes it difficult for them to get off from this kind of life. It takes time and it slows down their advantage, but once they got the right way of thinking, they go quite quickly. Obviously it is very individual, every person is different ... every thing comes up at the end, to the point, how serious you are about the violin. It all depends from the circumstances for many children, how they will go. If they keep their goal clear or the teacher gives the goal of the development clearly, what they have to achieve, then they'll go very quickly and go to a very high degree. (Interview with Ivan and Snejana Lazarov, 3 September 2005)

\section{Questions asked of STTEP pupils}

In 2009 the first author distributed questionnaires to all STTEP pupils, in an effort to check the extent to which they, as modern township residents, were conscious of the concept of Ubuntu. The questions asked were:

1. Do you know the word Ubuntu? (Yes or No)

2. If you know the word, please explain.

3. Do you know the longer saying: Umuntu ngumuntu ngabantu? (Yes or No)

4. If so, please add anything you want to your explanation of Ubuntu above.

5. Do you know the longer saying: Umntu ngumntu ngabanye abantu? (Yes or No)

6. If so, please add anything you want to your explanation of Ubuntu above.

7. Do you know the longer saying: Motho ke motho ka batho? (Yes or No)

8. If so, please add anything you want to your explanation of Ubuntu above.

Twenty responses were received, from pupils aged 10-20. Responses were similar from all students, across the age span, with all indicating that they understood the Ubuntu concept, and also as expressed in longer versions such as umuntu ngumuntu ngabantu and also Motho ke motho ka batho, which is in one of the indigenous languages (Sotho) spoken particularly widely in the Tshwane area. In all their answers words such as 'helpful', 'respectful', 'kind', 'merciful', 'sharing', 'caring', 'humane', 'generous', 'compassionate' and 'trusting' were mentioned. One pupil referred to 'people working as a unit within a nation'; another to 'people working together to make each other fulfil anything in a specific field in life'. An interesting response was 'You only earn respect from people if you also respect them' while one of the youngest (age 10) noted 'Ubuntu means that a person must consider others and not your own interest alone. People must act in one another's interests and not be selfish.' 


\section{Questions asked of STTEP staff}

Questionnaires were also distributed to the STTEP teachers - a total of 15 in number. To these the responses were decidedly poor: only five forms were received back, after waiting for and following up for weeks. Those forms returned were very hastily filled in, with the majority of answers to the effect that they had no idea of the meaning of Ubuntu. One gave the reasonable description 'unity/togetherness', and one the excellent and original answer 'I for you and you for me'. The second author is aware that this answer must have come from Julie Clifford, as she mentioned this formulation, too, in a telephonic discussion. During a Board meeting on 14 October 2008 she also spoke about 'giving (the pupils) something else in their lives - for the rest of their lives - and something which they can both do on their own and share.' Julie Clifford's personal manifestation of the spirit of Ubuntu also shines through the reporting of the work of the school, as evidenced by the following substantial extract from the 2008 annual report:

STTEP's beginner classes serve as an introduction to our teaching method and help the children and their families understand the commitment needed to make progress ...

Twelve new beginners were registered in January and they progressed very quickly, showing off their skills on recorder and percussion in school orchestra at the end of each Saturday. Every child passed a special test in May and began their lessons on orchestral instruments in July. This allowed us to register six more children from our waiting list... All of our beginners completed the year successfully and were voted the best yet by the rest of the school - quite an accolade!

Ensemble playing is an important part of our teaching method but of course, each pupil also needs to have personal achievements recognised.

In 2008, we held internal technical examinations in term 1, progress concerts at the end of terms 2, 3 and 4 and our annual 'Musician of the Year' competition in November. Ten pupils were entered for the TrinityGuildhall examinations ... We also introduced 'Spotlight', a weekly informal performance time organised by the pupils.

STTEP's internal examinations are compulsory for all pupils who have had lessons on orchestral instruments for more than 2 terms ... There can be no doubt that our musicians were serious about these examinations although some underestimated the amount of work they needed to do and were disappointed with their results ...

Everyone prepared a solo for each of the progress concerts and the chance to shine before fellow students, teachers and families provided lots of motivation for extra practice. The performances in terms 2 and 3 were not formally assessed, but our pupils did, inevitably, assess each other - very enthusiastically!

The finalists for 'Musician of the Year' were chosen from the last progress concert performances, which were assessed by our teachers. The full range of abilities and instruments were represented in the competition and the overall winner was our oboe player Tebogo Shibambo, who also had two pupils among the finalists.

Mixed ability ensemble lessons provide a different kind of learning environment in which everyone can flourish. The music is arranged so that each pupil, whatever their level, can play a manageable part and there is always a friend to assist if problems 
arise. Generally, pupils are very aware of those who may be struggling and they take the initiative to help without any prompting.

This year, 16 friends, who were quite inexperienced players, formed their own mixed ability string ensemble, organised extra rehearsals during the holidays and entered the competitive Unisa Youth Music Festival. It was interesting that the majority of these pupils were rather timid soloists but as members of an ensemble, their confidence levels soared and the performances at the Festival were surprisingly accomplished ...

In an email on 18 March 2009 Julie wrote:

The ethos in STTEP is rather according to the principles of ubuntu. We aim to respect, help and take care of each other and work together whatever the differences. We, in this case means everyone, including the teachers. There are few difficulties with the pupils, but it does appear that some teachers seem only to exist for themselves, showing little or no interest in the 'bigger picture' ... I think the best way forward is to try for a different mentality in those we teach, by encouraging a sense of ubuntu from the beginning. ${ }^{16}$

Using the answers we had obtained to our questions and which we have set out in this section, we turned our attention to the consideration of the important research issue of musical identity.

\section{STTEP students and their (musical) identity/identities}

STTEP Music School students are no 'Peas in a cultural pod' ${ }^{17}$ They are widely surrounded by global culture, and usually several generations of their forefathers have already lived in the city area. It would be naive to blame the hobby of playing an orchestral instrument for destroying their traditions. In fact, among the interesting fusions they have started to play are some traditional songs and kwela music, ${ }^{18}$ using their Western instruments. It is clear that being exposed to different music cultures such as Western classical music and Finnish folk fiddelling has raised their interest in different cultures - including their own.

For the identity of STTEP pupils, their roles at the school or in the orchestra have become very important to them. A part of their self-concept has been formed in comparison to other players and to their role in the orchestra. In addition to forming real elements of the identity of the students, the hobby has also produced an important tool to be used in identity processes. Playing helps the youth in processing, adapting and analysing their feelings. Yet the contrast between a formal violin performance and a traditional relaxed singing and dancing event during a music camp is striking, and these researchers, plus other Finns involved in the project, wonder to what extent the pupils' musical identity is yet solidly established. It is, for example, notable that playing orchestral instruments, some pupils have suffered from the same kind of performance anxiety familiar to many Western classical music students.

The second author noticed in South Africa that many music students saw violin playing as something special. Many held a violin in their hands for the first time and were really interested in making music. She found students motivated, excited, grateful and always ready to try. They were not so self-critical (if compared with European students) as to how and what they played; the most important thing was enjoying the music. The biggest 
difference between Finland and South Africa, she observed, was the understanding of what is a master violinist - due to lack of experience and standards of comparison, some South African students felt this could be achieved after half a year's study!

Further comparative aspects between Finnish/European and STTEP music students have been noted in research experiments conducted by colleagues of the authors, based at the University of Jyväskylä. In a study by Toiviainen and Eerola (2003), it was not surprising that the research results showed the African students not to differ significantly from the European group with respect to the mechanisms employed in finding the pulse in European melodies. However, results suggested that the African group utilised style-specific knowledge in deducing the beat in the African melodies.

A 2006 article by Eerola et al. reports on further research utilising STTEP pupils in comparison with 36 Finnish participants. A cross-cultural comparison was used to investigate the ratings of melodic complexity of Western and African participants for Western and African folk songs. This research suggests that melodic complexity ratings are influenced by musical enculturation, posing important questions in connection with the directions followed by the STTEP project.

\section{Conclusions and considerations for further research}

The results of the second author's research confirm the assumption that cultures affect teaching, which in the case of STTEP appears as different ways of teaching and different music education systems. Multicultural situations are indeed challenging to teachers and despite being aware thereof, the teacher's position remains very challenging as his or her own culture influences himself or herself. When meeting a pupil from a different culture a process begins where a teacher has to question his or her own behaviour and values and possibly leave out familiar things because of pupils' different ways of learning music. This process often opens new ideas, gives a greater meaning to cultural understanding and develops respect. These multicultural meetings are educative for all concerned, where every person is both sender and receiver.

'Cocooning' ${ }^{19}$ is not successful in the maintenance, let alone continuation and development, of culture. This knowledge was the raison d'être of the initial Finnish development cooperation project with STTEP. Having survived for over 13 years, STTEP has proved itself remarkably sustainable, ${ }^{20}$ in comparison with many other similar projects. And in all this time, rather than having a deleterious effect on the students' traditional culture, their involvement and identification with the music of an 'other' culture (if Western classical music can be so described) has actually awakened and strengthened students' interest in their cultural heritage and traditions.

What can Westerners in general learn from the social, African way of learning and playing music when mistakes made could even be described as joyous occasions, demonstrative of shared humanity and not of shame? ${ }^{21}$ If cultural outsiders are concerned about the 'saving' of traditional African music culture, can they not as well learn some elements from it, and apply them, too, within Western music and its teaching? The authors of this article envisage 'Umuntu ungumuntu ngabantu' as offering a great deal to education, and specifically music education, around the world. 


\section{Notes}

1 In their 2005 Dictionary of Music Education: A Handbook of Terminology, Ely and Rashkin note that 'Intercultural education involves promoting and encouraging cultural views in an objective manner' (p. 221). In this entry they refer to another entry under Multicultural Music Education, and there it is noted that 'there are many other valid forms of musical expression apart from Western traditions' (p. 276). This has certainly never been denied within the STTEP project. In fact, STTEP can claim to promote 'equity pedagogy' which 'speaks to program delivery that reflects multicultural issues and concerns, which in turn facilitates the achievement and development of students from diverse racial, gender, social-class and other cultural groups' (Meier n.d., p. 4).

2 This acronym acknowledges the South African Music Education Trust (S), the Tshwane district (T), under which Pretoria falls, and the then Transvaal Philharmonic Orchestra (T), no longer in existence, followed by EP for Education Project.

3 Although STTEP is referred to as a school, the different aspects of music taught to participants constitute more of a hobby than a formal, school-type subject.

4 Various terms are used for STTEP participants: children, learners, pupils, students, youth. Participants' ages vary from 4 upwards. At first one of STTEP's problems was that only older children and teenagers started instrumental lessons, allowing insufficient time for them to develop more than fairly basic instrumental skills. One of the project's successes has been that children of an increasingly younger age have gradually applied to register; this greatly improves their chances of developing higher level performance skills. The downside is that sometimes the opinion has been expressed, even by participants themselves, that the school is used by parents as a 'babysitting' service.

5 According to Wikipedia (accessed 18 June 2008), 'In South Africa, the term township usually refers to the (often underdeveloped) urban living areas that, under Apartheid, were reserved for non-whites.'

6 Järvelä was due to return in February 2009 to South Africa for another session of working with the STTEP pupils, but due to health problems this proved not possible. However, several colleagues were still able to come and once again work with STTEP pupils, mainly according to the Nappari pedagogy in which they are particularly expert.

7 The humanist African Ubuntu philosophy is explained under the heading Ubuntu.

8 Philip's death in 2007 was a huge blow to the STTEP project, which has nevertheless managed to continue, due chiefly to the sterling efforts and great personal sacrifices of his widow Julie.

9 For example, Philip Clifford wrote in an email to the first author, dated 1 March 2007: 'By coincidence, AmAcademy [note: see reference later in the article to this more specialised STTEP orchestra] had a lengthy discussion on Sunday concerning the members' obligations to each other, or ethical entanglements with each other. We eventually agreed that these bonds are most keenly felt in musical matters; that we want to hear each other play, to play with each other, and that Johann Sebastian's or Amadeus's music comes second.'

10 One of the results of Apartheid (see note xii) is that not only were different racial groups (Whites, Blacks, Coloureds and Indians) separated from each other, but also Black people who had been living together in an area were uprooted, because their presence there was deemed unwanted, and sent to different townships, some of which could be quite far from each other.

11 'As soon as intercultural pedagogy is seen as enlightening practice, its contrast to affirmation becomes decisive and radical ... With regard to its empirical principles intercultural pedagogy has to define itself within the enlightened practice and within societal organisation and movement. The ideological terrain of racism, cultural racism and cultural colonialism must be drained. The substantive task of the practice of interculturality is to break racism' (Buttjes \& Byram, 1991, p. 281).

12 Apartheid was the policy/system of segregation or discrimination on grounds of race of the previous Nationalist party government in South Africa. The families of pupils referred to in this article as living in 'townships' around the main city of Pretoria would have been forced, under Apartheid, to live there. 
13 This can be the case even with a Finnish teacher, such as the second author of this article - and even bearing in mind all that Finns have done for STTEP, both financially and in practical teaching terms.

14 This article does not go into the extensive literature on the often confusing explications of differences between multi-, inter- and cross- or trans-cultural education. Here, however, only the terms intercultural and multicultural are used: the two terms which, according to a wide range of authors, are virtually interchangeable and which Schippers (2010, p. 31) positions adjacent to one another on his continuum of approaches to cultural diversity.

15 This name was thought of in line with the name for the South African rugby team, the Springboks, who became known as Amabokkebokke. The South African national under-23 soccer team is known colloquially as Amaglug-glug. The prefix 'ama' denotes the Zulu plural form. Thus AmAcademy is a combination of ama (the people (of)) and Academy.

16 This bears out the quotation from Cushner (1998), given above: 'Although education alone cannot change the face of many problems that exist today, it can influence the future by preparing the minds of young people to include a diversity of viewpoints, behaviors and values.'

17 This expression is borrowed from the title of a 2004 article by Dawn Bennett in the Australian Journal of Music Education.

18 Kwela is a happy, often pennywhistle-based, street music with jazzy underpinnings.

19 'Cocooning' is the name given to the trend where individuals socialise less and retreat into their home more. The term was coined in the 1990s by Faith Popcorn, a trend forecaster and marketing consultant, who identified cocooning as a commercially significant trend. However, apart from these commercial aspects, it is also possible to think of this term specifically in relation to cultural heritage and its preservation, as opposed to openness to what can be gained from other cultures.

20 Sadly, since the return of Julie Clifford to the UK towards the end of 2009, STTEP is no longer functioning as successfully as previously.

21 One Westerner who has realised this, and propagates it strongly (together with his wife) in his book The Art of Possibility, is the conductor of the Boston Philharmonic Orchestra, Benjamin Zander. His presentations on his ideas and practices, too, are hailed with huge enthusiasm all over the world. He writes: 'I actively train my students that when they make a mistake, they are to lift their arms in the air, smile, and say, 'How fascinating!' I recommend everyone try this ... Not only mistakes, but even those experiences we ordinarily define as 'negative' can be treated in this way' (Zander \& Zander, 2000, p. 31). As long ago as 1975 the Canadian composer and music educator Murray Schafer, in his 10 Maxims for Music Educators, chose first to list 'The first practical step in any educational reform is to take it' and secondly 'In education, failures are more important than successes. There is nothing so dismal as a success story' (Schafer, 1975, p. 2). Yet neither of these authors mention African ways of learning and playing music, or Ubuntu, a pre-colonial concept rooted and practised in Africa.

\section{References}

BALL, P. (2010) The Music Instinct. London: The Bodley Head.

BELZ, J. A. \& MÜLLER-HARTMANN, A. (2003) Teachers as intercultural learners: negotiating GermanAmerican telecollaboration along the institutional fault line. Modern Language Journal, 87 (1), 71 89.

BENNETT, D. (2004) Peas in a cultural pod? A comparison of the skills and personal attributes of artists and musicians. Australian Journal of Music Education, 1, 53-60.

BENNETT, M. (1993) Towards ethnorelativism: a developmental model of intercultural sensitivity. In R. M. Paige (Ed.), Education for the Intercultural Experience (pp. 21-71). Yarmouth, ME: Intercultural Press. BROODRYK, J. (2002) UBUNTU - Life Lessons from Africa. Pretoria: Ubuntu School of Philosophy.

BUTTJES, D. \& BYRAM, M. (1991) Mediating Languages and Cultures: Towards an Intercultural Theory of Foreign Language Education. Clevedon: Multilingual Matters. 
CUSHNER, K. (1998) International Perspectives on Intercultural Education. London: Lawrence Erlbaum Associates.

EeROLA, T., HIMBERG, T., TOIVIAINEN, P. \& LOUHIVUORI, J. (2006) Perceived complexity of Western and African folk melodies by Western and African listeners. Psychology of Music, 34, 341-375.

ELDERING, L. (1996) Multiculturalism and multicultural education in an international perspective. Anthropology and Education Quarterly, 27, 315-330.

ELY, M. C. \& RASHKIN, A. E. (2005) Dictionary of Music Education: A Handbook of Terminology. Chicago: GIA Publications.

HIRSJÄRVI, S. \& HURME, H. (2000) Tutkimushaastattelu: Teemahaastattelun teoria ja käytäntö. Helsinki: Yliopistopaino.

ILARI, B. (2010) A community of practice in music teacher training: The case of Musicalização Infantil. Research Studies in Music Education, 32(1), 43-60.

JANDT, F. E. (2004) Intercultural Communication: A Global Reader. Thousand Oaks, CA: Sage.

KAFAI, Y., DESAI, S., PEPPLER, K., CHIU, G. \& MOYA, J. (2008) Mentoring partnerships in a community technology centre: a constructionist approach for fostering equitable service learning. Mentoring and Tutoring, 16, 191-205.

LEBLANC, A. (1982) An interactive theory of music preference. Journal of Music Therapy, 19, 28-45.

LEEMAN, Y. \& REID, C. (2006) Multi/intercultural education in Australia and the Netherlands. Compare: A Journal of Comparative Education, 36 (1), 57-72.

MCALLISTER, G. \& IRVINE, J. J. (2000) Cross cultural competency and multicultural teacher education. Review of Educational Research, 70(1), 3-24.

MEIER, A. L. (n.d.) Defining Multicultural Education Fact Sheet 07-53. http://www.unce.unr.edu/ publications/files/cy/2007/fs0753.pdf (Retrieved 27 June 2008).

MOUTON, J. (2001) How to Succeed in your Masters \& Doctoral Studies. Pretoria: Van Schaik.

NORTH, A. C. \& HARGREAVES, D. J. (1999) The functions of music in everyday life: redefining the social in music psychology. Psychology of Music, 27, 71-83.

PINTRICH, P. R. \& SCHUNK, D. H. (2002) Motivation in Education: Theory, Research and Applications. Englewood Cliffs, NJ: Prentice-Hall.

RAUF, D. (2006) It's all about the music. Careers and Colleges, 26 (3), 4-7.

SCHAFER, R. M. (1975) The Rhinoceros in the Classroom. London: Universal Edition Canada.

SCHIPPERS, H. (2010) Facing the Music: Shaping Music Education from a Global Perspective. Oxford: Oxford University Press.

TOIVIAINEN, P. \& EEROLA, T. (2003) Where is the beat?: Comparison of Finnish and South African listeners. Proceedings of the $5^{\text {th }}$ Triennial ESCOM Conference, 8-13 September 2003, pp. 501-504.

VAN NIEKERK, C. \& SALMINEN, S. (2008) Sttepping in the right direction? Western classical music in an orchestral programme for disadvantaged African youth. Journal of Intercultural Education 19 (3), 191-202.

WHITE, K. S. (2008) A performer's guide to American art song outreach in elementary schools. DMA, University of Kentucky.

WOODROW, D., VERMA, G. K., ROCHA-TRINDADE, M. B., CAMPANI, G. \& BAGLEY, C. (1997) Intercultural Education: Theories, Policies and Practice. Ashgate: Aldershot.

ZANDER, R. S. \& ZANDER, B. (2000) The Art of Possibility. Cambridge, MA: Harvard Business School Press.

ZILLMAN, D. \& GAN, S. (1997) Musical taste in adolescence. In D. J. Hargreaves \& A. C. North (Eds), Social Psychology of Music, pp. 161-187. Oxford: Oxford University Press. 